\title{
Stereoselective Decarboxylative Alkylation of Titanium(IV) Enolates with Diacyl Peroxides
}

\author{
Alejandro Gómez-Palomino, ${ }^{\dagger, \dagger, \&}$ Marina Pérez-Palau, ${ }^{\dagger \dagger}$ Pedro Romea, ${ }^{* \dagger}$ Fèlix Urpí, ${ }^{*, \dagger}$ Marc Del \\ Olmo, ${ }^{\dagger}$ Timo Hesse, ${ }^{\dagger,}$ Sonja Fleckenstein, ${ }^{\dagger,}$ Enrique Gómez-Bengoa, ${ }^{*, \diamond}$ Lia Sotorríos, ${ }^{\diamond}$ and Mercè \\ Font-Bardia ${ }^{\#}$
}

† Secció de Química Orgànica, Departament de Química Inorgànica i Orgànica and Institut de Biomedicina de la Universitat de Barcelona (IBUB), Universitat de Barcelona, Carrer Martí i Franqués 1-11, 08028 Barcelona, Catalonia, Spain

$\diamond$ Departamento de Química Orgánica I, Universidad del Pais Vasco, UPV/EHU, Apdo. 1072, 20080 San Sebastián, Spain

\# Unitat de Difracció de RX. CCiTUB. Universitat de Barcelona. Carrer Solé i Sabarís 1-3, 08028 Barcelona, Catalonia, Spain

Supporting Information Placeholder

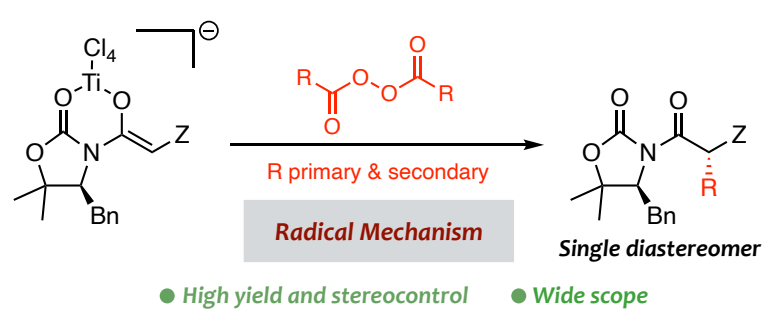

\begin{abstract}
Simple treatment of chiral titanium(IV) enolates with diacyl peroxides produces highly diastereoselective decarboxylative alkylations to efficiently deliver the corresponding adducts, most of which are not accessible through any of the current alkylating procedures. Such an unprecedented alkylation proceeds through a SET process that triggers the decomposition of the peroxide into a carbon-centered radical that finally combines with the resulting $\mathrm{C} \alpha$ radical. The procedure has been applied to the enantioselective synthesis of arundic acid.
\end{abstract}

The stereocontrolled construction of the carbon backbone of chiral molecules is at the core of asymmetric synthesis. ${ }^{1}$ One of the simplest approaches to meet such challenge hinges on the alkylation of the $\mathrm{C} \alpha$ position of carbonyl compounds. ${ }^{2}$ Indeed, the alkylation of alkaline enolates of chiral $\mathrm{N}$-acyl oxazolidinones $^{3}$ and pseudoephedrines ${ }^{4,5}$ hold a prominent position among the carbon-carbon bond forming reactions and usually remain the method of choice for the synthesis of natural products. ${ }^{6,7}$ These, as well as related methods, ${ }^{8-10}$ proceed through a $\mathrm{S}_{\mathrm{N}} 2$ mechanism so their scope is restricted to a set of privileged electrophiles (Scheme 1). Furthermore, Evans reported that titanium(IV) enolates of chiral $\mathrm{N}$-acyl oxazolidinones may undergo stereoselective $\mathrm{S}_{\mathrm{N}} 1$-like alkylations with certain oxocarbenium intermediates (Scheme 1). ${ }^{11}$ Therefore, and despite the undeniable success of such approaches, there is still a need for a wide breadth of $\mathrm{C} \alpha$ alkylating methods that enable the stereoselective introduction of any alkyl group without requiring strong bases in the enolization step that may thwart their application to sensitive substrates. A compelling manner to address such a challenge involves the use of radical intermediates that undergo homolytic reactions. ${ }^{12-14}$ Unfortunately, carbon-centered radicals are highly reactive species, which can only be produced from a small number of substrates. ${ }^{15}$
Herein, we disclose a different concept to overcome the abovementioned limitations. This calls for the unprecedented stereoselective alkylation of titanium(IV) enolates with diacyl peroxides through a homolytic mechanism. Indeed, a single electron transfer from the enolate to the peroxide triggers a mesolytic cleavage and consequent decarboxylation, which leads to the formation of a carbon-centered radical that combines with the enolate. As represented in Scheme 1, this new approach relies on the diradical character of titanium enolates ${ }^{16-}$ 19 and the weak oxygen-oxygen bond of peroxides. Synthetically, it allows the straightforward and stereoselective alkylation of chiral imides including their $\alpha$-chloro, $\alpha$-amino, and $\alpha$ hydroxy counterpart with a large variety of $\mathrm{R}$ groups. Therefore, this method combines simplicity and robustness, which makes possible the highly chemo and stereoselective introduction of primary and secondary alkyl groups that are not easily amenable to any other current alkylation method.

In our search for new reactivity of titanium(IV) enolates based on their diradical character, we envisaged that diacyl peroxides might be a suitable source for carbon-centered radicals. $^{20,21}$ Initially, we explored the stereoselective alkylation of titanium(IV) enolates of chiral $N$-propanoyl oxazolidinone $\mathbf{1}^{22}$ with commercially available benzoyl peroxide (BPO) and lauroyl peroxide (LPO) shown in Scheme 2. Benzoyl peroxide did 
Scheme 1. Stereoselective Alkylations

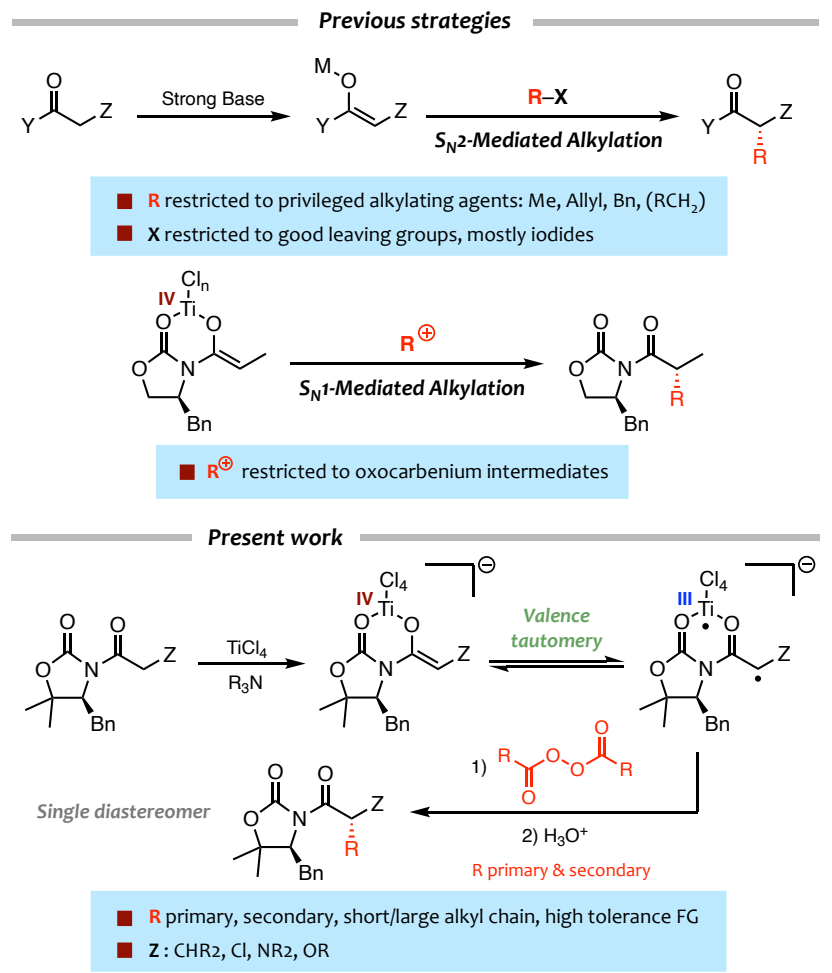

not undergo the desired carbon-carbon bond forming reaction and afforded instead $\alpha$-benzoyloxy adduct $\mathbf{2}$ in acceptable yields but moderate diastereoselectivity. Otherwise, lauroyl peroxide (LPO) proceeded as expected and produced a single undecyl-derived diastereomer 3a (Scheme 2).

\section{Scheme 2. Reactions of Titanium(IV) Enolate from 1 with Diacyl Peroxides}

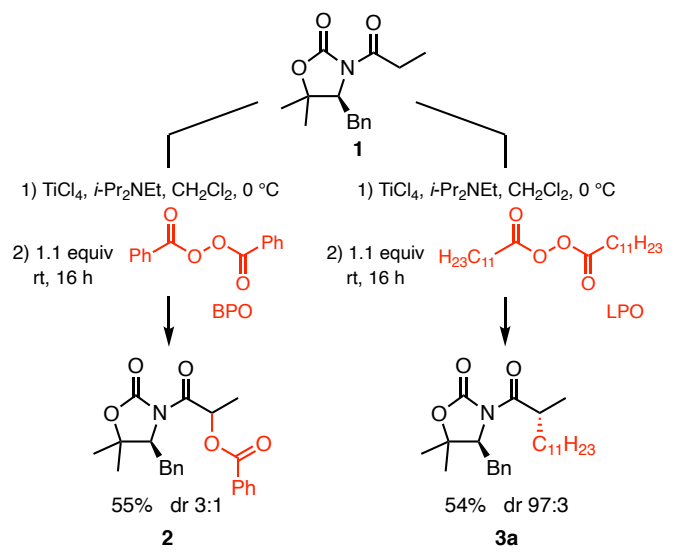

A detailed examination of the reaction showed the benefits of working with an excess of LPO. Increasing amount of peroxide provided higher yields and kinetic rates up to a point in which the alkylation of $\mathbf{1}$ was completed in less than $2 \mathrm{~h}$ and afforded $76 \%$ of $3 \mathbf{a}$ with 3 equivalents of LPO. Larger quantities of LPO resulted superfluous (Table S1). With the optimal amount of peroxide determined, we also established that changes in the temperature or concentration, as well as the use of other titanium(IV) Lewis acids or a less bulky oxazolidinone did not improve the outcome of the alkylation (Table S2). Interestingly, we observed along these studies the formation of traces of $\mathbf{I}$ and significant amounts (5-10\%) of dichloromethyl derivative II (Figure 1), which further suggested the involvement of radicals in the alkylating pathway. Thus, we decided to evaluate the influence of other chlorinated solvents.<smiles>CC(Cl)C(=O)N1C(=O)OC(C)(C)C1Br</smiles><smiles>CC(CCl)C(=O)N1C(=O)OC(C)(C)C1Br</smiles>

Figure 1. By-products of the Decarboxylative Alkylation

Gratifyingly, the solvent had a dramatic impact on the alkylation. Indeed, $\mathrm{CCl}_{4}$ and $\mathrm{CHCl}_{3}$ proved to be completely unsuitable, 1,1,2,2-tetrachloroethane (TCE) gave similar results to $\mathrm{CH}_{2} \mathrm{Cl}_{2}$, but 1,2-dichloroethane (DCE) afforded 3a in a higher yield without being contaminated by the corresponding analog of II (Table S3). Then, following a comprehensive survey of the alkylation in DCE (Table S4) ${ }^{16}$ we established that the use of 3 equivalents of $\mathrm{Et}_{3} \mathrm{~N}$ and just 1.5 equivalents of $\mathrm{LPO}$ allowed us to isolate diastereomerically pure 3a with a $93 \%$ yield (Scheme 3).

\section{Scheme 3. Optimized Alkylation of 1 with LPO}

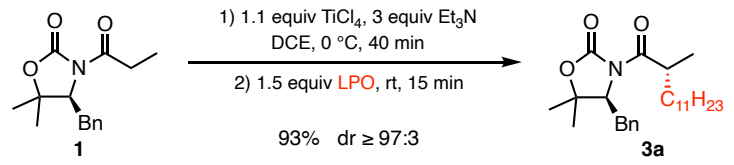

Having improved the experimental procedure, we assessed the scope of the reaction by applying the optimized conditions to other diacyl peroxides. ${ }^{23}$ The results summarized in Scheme 4 show that our protocol affords a single diastereomer ( $\mathrm{dr} \geq$ $97: 3$ ) in yields of up to $95 \%$. Noteworthily, this is not only limited to primary alkyl groups $\mathbf{3 a - 3 d}$ but may also be applied to

\section{Scheme 4. Scope of the Alkylation of $1^{\mathrm{a}, \mathrm{b}}$}
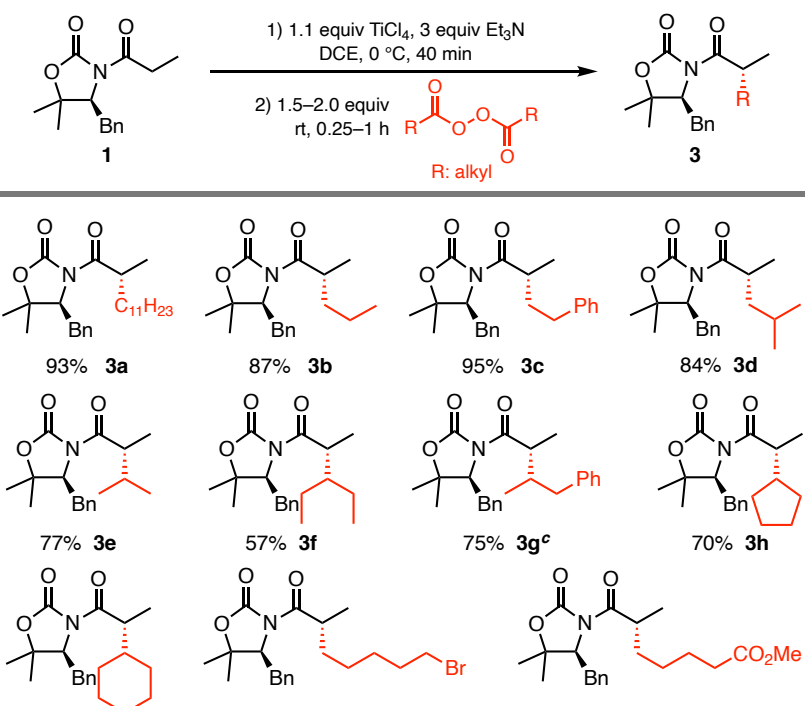

$87 \%$ 3b

$95 \% \quad 3 c$

$84 \%$ 3d
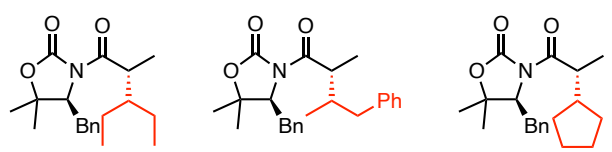

$75 \% \mathbf{3 g}^{c}$
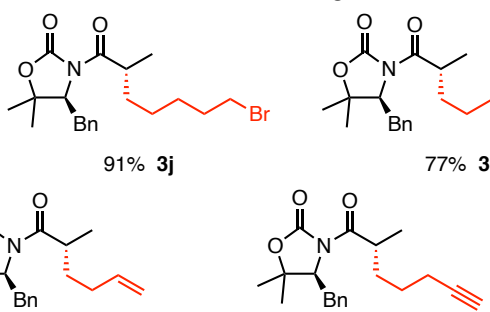

$74 \% 3 \mathbf{i}$

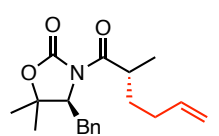

$93 \% 31$
$91 \% 3 m$
${ }^{a}$ Isolated yield. ${ }^{b} \mathrm{dr} \geq 97: 3 .{ }^{c} \mathrm{dr} 2: 1$ at $\mathrm{C} \beta$ 
secondary alkyl groups $\mathbf{3 e}-\mathbf{3 i}$. Indeed, the method permits the introduction of isopropyl (3e), 3-pentyl (3f), 1-phenyl-2-propyl $(\mathbf{3 g})$, cyclopentyl (3h), or cyclohexyl (3i) groups in high yields, a range of substrates that had proven elusive to other alkylation procedures. Finally, we were delighted to observe that the alkylation with diacyl peroxides containing halides, esters, double, and triple bonds also led to the isolation of a single diastereomer of adducts $\mathbf{3} \mathbf{j}-\mathbf{3} \mathbf{m}$ in high to excellent yields. Furthermore, the tolerance of these functional groups is remarkable and highlights the outstanding chemoselectivity of the process.

In view of such results, we next examined the robustness of the acyl group. As summarized in Scheme 5, the alkylation of increasingly sterically hindered substrates both at the $\mathrm{C} \alpha$ acyl group $(Z)$ and the radical $(R)$ is possible. Indeed, substrates 1 and 4 containing unhindered acyl groups $(Z$ : $M e, E t)$ react with diacyl peroxides a and $\mathbf{c}$ to give $\mathbf{3 a}, \mathbf{3 c}, \mathbf{1 5 a}$, and $\mathbf{1 5} \mathbf{c}$ as a single diastereomer $(\mathrm{dr} \geq 97: 3)$ in excellent yields (73-95\%), whereas parallel reactions with the more bulky diacyl peroxide i provided adducts $\mathbf{3 i}$ and $\mathbf{1 5 i}$ in good yields (51-74\%). Likewise, alkylation of a more hindered substrate 5 (Z: $i$-Pr) with diacyl peroxides a, $\mathbf{c}$, and $\mathbf{i}$ also gave adducts $16 \mathbf{a}, 16 \mathbf{c}$, and $16 \mathbf{i}$ with notable efficiency (20-67\%). At this point, configuration of the

\section{Scheme 5. Scope of the Alkylation of $N$-Acyl Oxazoli- dinones $^{a, b}$}

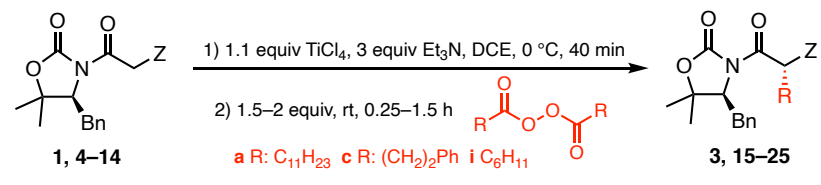

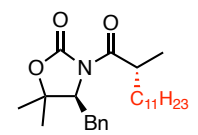

$93 \%$ 3a

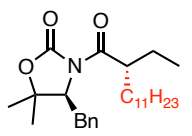

$88 \% \quad 15 a$

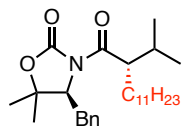

$65 \% \quad 16 a$

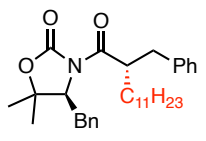

$67 \% \quad 17 a$

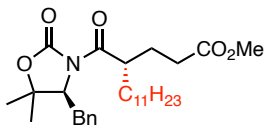

$83 \% 20 a$

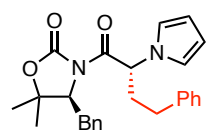

$66 \%$ Major dr 94:6 23c

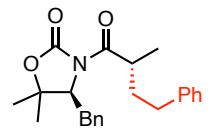

$95 \% \quad 3 c$

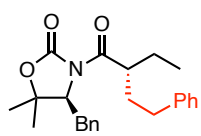

$73 \% \quad 15 c$

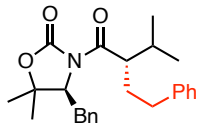

$67 \%$ 16c

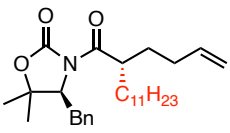

$60 \% \quad 18 a$

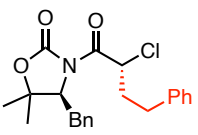

$(93 \%)^{c}$ dr 85:15 21c

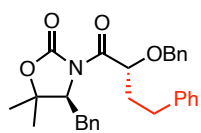

$82 \% 24 c^{e}$

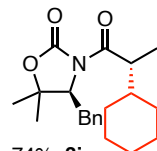

$74 \% \mathbf{3 i}$
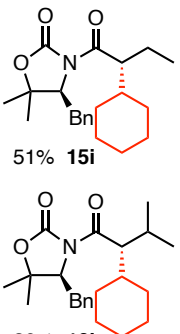

$20 \% 16 i$

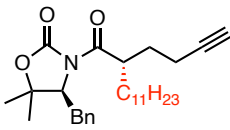

$81 \% \quad 19 a$

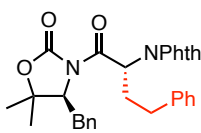

$30 \% 22 \mathrm{c}$

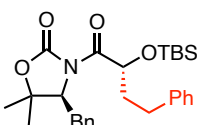

$85 \% 25 c^{f}$
${ }^{a}$ Isolated yield. ${ }^{b} \mathrm{dr} \geq 97: 3 .{ }^{c}$ Overall yield. ${ }^{d}$ Reaction at $-20{ }^{\circ} \mathrm{C}$. ${ }^{e}$ Reaction at $0{ }^{\circ} \mathrm{C}$. ${ }^{f}$ Reaction at $-10{ }^{\circ} \mathrm{C}$
$\mathrm{C} \alpha$ chiral center was firmly established by X-ray analysis of 16c. ${ }^{24}$ Importantly, substrates containing phenyl, alkene, alkyne, or ester groups proved suitable and gave adducts $\mathbf{1 7 a - 2 0 a}$ with a $60-83 \%$ yield. Furthermore, the alkylation resulted compatible with $\mathrm{C} \alpha$ heteroatoms. Thereby, alkylation of $N$-chloroacetyl oxazolidinone $(\mathrm{Z}: \mathrm{Cl})$ with diacyl peroxide c produced the $\alpha$-chlorinated adduct 21c as an 85:15 diastereomeric mixture with a $92 \%$ overall yield. Even the alkylation of $\alpha$-nitrogenated substrates resulted feasible and pyrrole-derived oxazolidinone ( $\mathrm{Z}$ : pyrrole) afforded a 94:6 diastereomeric mixture from which 23c was isolated in a $66 \%$ yield. Eventually, $\alpha$-hydroxy substrates (Z: OBn, OTBS) were also found to be appropriate and produced adducts $24 \mathrm{c}$ and $25 \mathrm{c}$ in an $82-85 \%$ yield. All together, these results show that the appropriate choice of the $\mathrm{Z}$ group may give a straightforward access to a remarkable range of enantiomerically pure $\alpha$-halo, $\alpha$-amino, and $\alpha$-hydroxy acids. ${ }^{25}$

Having demonstrated the wide scope and the robustness of the alkylation, we focused our attention on its mechanism. Our working hypothesis revolved around the diradical character of the titanium(IV) enolates ${ }^{16,17}$ of $\mathbf{1}$. The isolation of small quantities of dichloromethyl derivative II (Figure 1) supported such a hypothesis, but further proof was required. In this context, the alkylation with the diacyl peroxide from 2-cyclopropylacetic acid (n) was crucial. Importantly, we only observed the formation of the open-chain adduct 3l (Scheme 6), which is strong evidence that the decarboxylative alkylation proceeds through the addition of radicals to the titanium(IV) enolates. ${ }^{26}$

\section{Scheme 6. Mechanistic Studies}

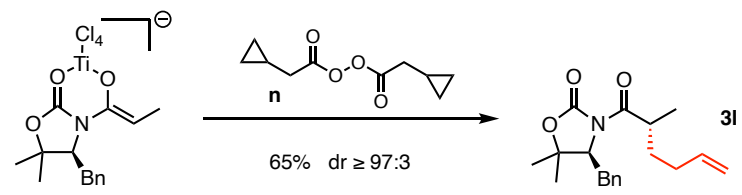

In parallel, we carried out a computational analysis to gain insight into the mechanistic details of the process. Keeping in mind the diradical character of the titanium(IV) enolates, ${ }^{16,17}$ we thoroughly examined the addition of the titanium(IV) enolate from 1 to the model dilauroyl peroxide (Scheme 7). Thereby, it was found that the reaction proceeds through an electron transfer from the $\alpha$-carbon in III to the $\sigma^{*}$ orbital of the $\mathrm{O}-\mathrm{O}$ bond in a Single Electron Transfer (SET) redox reaction, which gives radical IV, causes the cleavage of the $\mathrm{O}-\mathrm{O}$ bond into a carboxylate anion and a radical ( $\mathbf{V}$ and VI respectively). Then, the spontaneous decarboxylation of VI produces a carbon-centered radical VII that may combine with $\mathrm{IV}$ to form the $\mathrm{C}-\mathrm{C}$ bond. At this point, we cannot rule out the possibility that the key $\mathrm{C}$ $\mathrm{C}$ bond can be formed by reaction of the alkyl radical VII with III (instead of IV) in a radical chain reaction, more complex than the depicted in Scheme 7 (for further details, see the Supporting Information).

In any case, a SET mechanism may account for the experimental results. Indeed, this involves alkyl radical intermediates, which explains the occurrence of compounds like $\mathbf{3 1}$ and byproduct II. Remarkably, the overall transformation is energetically feasible $\left(\Delta \mathrm{G}=-16.6 \mathrm{kcal} \mathrm{mol}^{-1}\right)$. Furthermore, the reagents must approach to a short distance for the electron transfer to occur, and due to the bulkiness of III and the diacyl peroxides 
a good diastereoselectivity is ensured (Scheme 7). Thereby, a remarkable minimum energy difference of at least $3.5 \mathrm{kcal} \mathrm{mol}^{-}$

${ }^{1}$ for the approach to both $\pi$-faces in the electron transfer structure at $\mathrm{C}-\mathrm{O}$ distances ranging from 1.8 to $4 \AA$ in distinct conformations was calculated, which corresponds to a dr $>99: 1$. Therefore, the proposal depicted in Scheme 7 accounts for both the observed reactivity and stereoselectivity, since carbon-centered alkyl radicals are involved in the reaction and the stereochemical outcome of the alkylation depends on the approach of the entire diacyl peroxide to the less sterically shielded $S i$ face of the enolate.

\section{Scheme 7. Mechanistic Hypothesis}

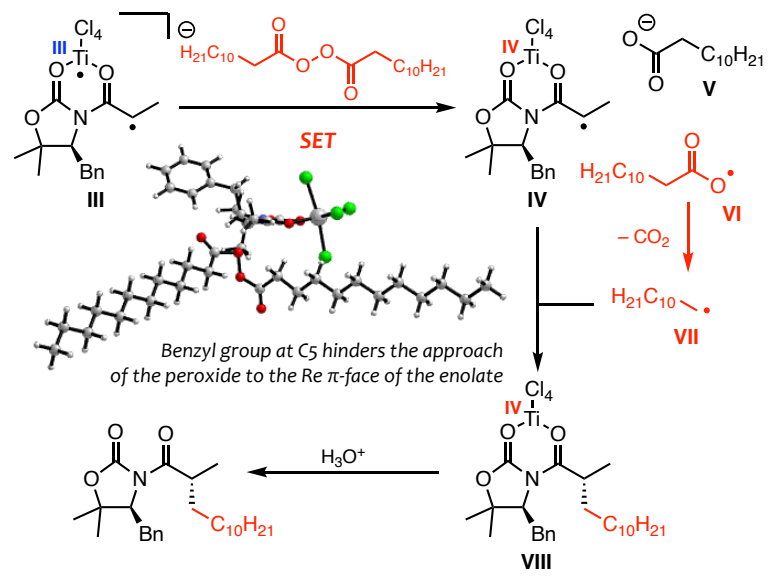

Finally, we considered the opportunity to apply the new method to the synthesis of arundic acid (26 in Scheme 8), a chiral carboxylic acid with potential neuroprotective activity. ${ }^{28}$ The synthesis commenced with a standard acylation of 27 to produce $N$-pentanoyl oxazolidinone $28 .{ }^{29}$ Then, treatment of the titanium(IV) enolate of $\mathbf{2 8}$ with diheptanoyl peroxide (o) provided a single diastereomer of the alkylated adduct 290 with an $87 \%$ yield at multigram scale. Next, removal of the chiral auxiliary afforded enantiomerically pure arundic acid $\mathbf{2 6}$ in $95 \%$ yield and complete recovery of $27 .{ }^{30}$ Therefore, arundic acid has been prepared with a $70 \%$ overall yield in a three-step sequence that involves the decarboxylative alkylation previously developed.

\section{Scheme 8. Enantioselective Synthesis of Arundic Acid}

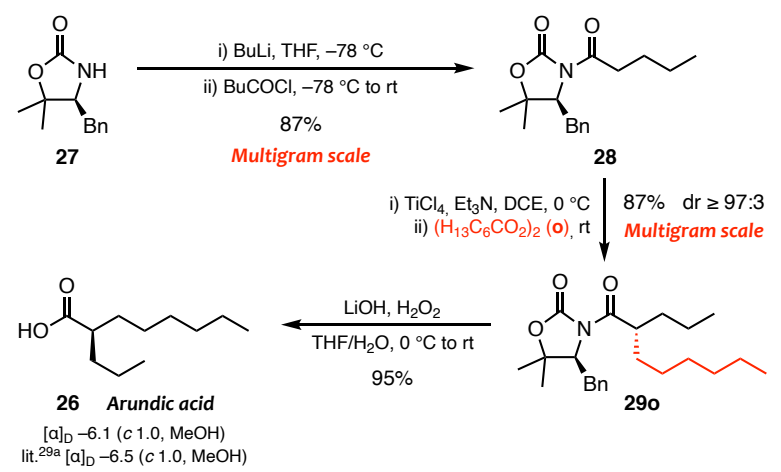

In summary, a highly stereoselective decarboxylative alkylation of the titanium(IV) enolates from a wide array of chiral $\mathrm{N}$ - acyl oxazolidinones with diacyl peroxides from primary and secondary aliphatic carboxylic acids is described. Experimental evidence and theoretical calculations indicate that the reaction takes advantage of the diradical character of the titanium(IV) enolate and proceeds through a SET step that triggers the decomposition of the diacyl peroxide. This proves for the first time that titanium(IV) enolates may behave as reducing agents and thus take part in radical transformations to afford enantiomerically pure alkylated products. Furthermore, this method has been applied to the enantioselective synthesis of the arundic acid at a multigram scale.

\section{ASSOCIATED CONTENT}

\section{Supporting Information}

The Supporting Information is available free of charge on the ACS Publications website.

Experimental details, compound characterization, and copies of ${ }^{1} \mathrm{H}$ and ${ }^{13} \mathrm{C}$ NMR spectra (PDF)

Crystallographic data for $\mathbf{1 6 c}(\mathrm{CIF})$

Details of theoretical calculations (PDF)

\section{AUTHOR INFORMATION}

\section{Corresponding Author}

* pedro.romea@ub.edu

* felix.urpi@ub.edu

* enrique.gomez@ehu.es

\section{Present Addresses}

\& A. G.-P: Max-Planck-Institut für Kohlenforschung (Germany) $\S$ S. F.: Institute of Organic Chemistry and Biochemistry. Technical University of Darmstadt (Germany).

q T. H.: Institute of Organic Chemistry. Leibniz University Hannover (Germany).

\section{Author Contributions}

$\$$ These authors contributed equally.

\section{Notes}

The authors declare no competing financial interest.

\section{ACKNOWLEDGMENT}

We thank Professor Paul Knochel (Ludwig-Maximilians-Universität München) for insightful comments on the use of pyrroles as amino protecting groups and David Casanova (DIPC, Donostia International Physics Center, San Sebastián) for helpful mechanistic discussions. Financial support from the Spanish Ministerio de Economía y Competitividad (Grant No. CTQ2015-65759-P), the Spanish Ministerio de Ciencia, Innovación y Universidades (MCIU)/Agencia Estatal de Investigación (AEI)/Fondo Europeo de Desarrollo Regional (FEDER, UE) (Grant No. PGC2018-094311B-I00), and the Generalitat de Catalunya (2017SGR 271) as well as doctorate studentships to A. G.-P. (APIF, Universitat de Barcelona), M. P.-P. (FPU, MCIU), and L. S. (MINECO, CTQ201678083-P) are acknowledged. We also thank IZO/SGI-SGIker of $\mathrm{UPV} / \mathrm{EHU}$ for human and computational resources.

\section{REFERENCES}

(1) Carreira, E. M.; Kvaerno, L. Classics in Stereoselective Synthesis; Wiley-VCH: Weinheim, 2009. 
(2) Stoltz B. M.; Bennett, N. B.; Duquette, D. C.; Goldberg, A. F. G.; Liu, Y.; Loewinger, M. M.; Reeves, C. M. Editors: Knochel, P.; Molander, G. A. Comprehensive Organic Synthesis (2 ${ }^{\text {nd }}$ Edition) 2014, 3, 1-20.

(3) Evans, D. A.; Ennis, M. D.; Mathre, D. J. Asymmetric Alkylation Reactions of Chiral Imide Enolates. A Practical Approach to the Enantioselective Synthesis of $\alpha$-Substituted Carboxylic Acid Derivatives. J. Am. Chem. Soc. 1982, 104, 1737-1739.

(4) Myers, A. G.; Yang, B. H.; Chen, H.; McKinstry, L.; Kopecky, D. J.; Gleason, J. L. Pseudoephedrine as a Practical Chiral Auxiliary for the Synthesis of Highly Enantiomerically Enriched Carboxylic Acids, Alcohols, Aldehydes, and Ketones. J. Am. Chem. Soc. 1997, 119, 6496-6511.

(5) Morales, M. R.; Mellem, K. T.; Myers, A. G. Pseudoephenamine: A Practical Chiral Auxiliary for Asymmetric Synthesis. Angew. Chem. Int. Ed. 2012, 51, 4568-4571.

(6) For a recent example, see: Rohrs, T. M.; Qin, Q.; Floreancig, P. E. $\mathrm{Re}_{2} \mathrm{O}_{7}$-Mediated Dehydrative Cyclization Reactions: Total Synthesis of Herboxidiene and Its 12-Desmethyl Analogue. Angew. Chem. Int. Ed. 2017, 56, 10900-10904.

(7) For a recent example, see: Lu, Z.; Zhang, X.; Guo, Z.; Chen, Y.; Mu, T.; Li, A. Total Synthesis of Aplysiasecosterol A. J. Am. Chem. Soc. 2018, 140, 9211-9218.

(8) Schöllkopf, U. Asymmetric Synthesis of Amino Acids Via Metalated Bis-Lactam Ethers of 2,5-Diketopiperazines. Pure \& Appl. Chem. 1983, 55, 1799-1806.

(9) Oppolzer, W. Camphor as a Natural Source of Chirality in Asymmetric Synthesis. Pure \& Appl. Chem. 1990, 62, 12411250 .

(10) Ooi, T.; Maruoka, K. Recent Advances in Asymmetric PhaseTransfer Catalysis. Angew. Chem. Int. Ed. 2007, 46, 42224266.

(11) Evans, D. A.; Urpí, F.; Somers, T. C.; Clark, J. S.; Bilodeau, M. T. New Procedure for the Direct Generation of Titanium Enolates. Diastereoselective Bond Constructions with Representative Electrophiles. J. Am. Chem. Soc. 1990, 112, 82158216.

(12) Sibi, M. P.; Ji, J. Acyclic Stereocontrol in Radical Reactions: $\rho$-Selectivity with Oxazolidinone Auxiliaries. Angew. Chem. Int. Ed. 1996, 35, 190-192.

(13) Beeson, T. D.; Mastracchio, A.; Hong, J.-B.; Ashton, K. MacMillan, D. W. C. Enantioselective Organocatalysis Using SOMO Activation. Science 2007, 316, 582-585.

(14) Capacci, A. G.; Malinowski, J. T.; McAlpine, N. J.; Kuhne, J.; MacMillan, D. W. C. Direct, Enantioselective $\alpha$-Alkylation of Aldehydes Using Simple Olefins. Nature Chem. 2017, 9, 1073-1077.

(15) For recent accounts on the importance of radicals in organic synthesis, see: (a) Smith, J. M.; Harwood, S. J.; Baran, P. S. Radical Retrosynthesis. Acc. Chem. Res. 2018, 51, 1807-1817. (b) Smith, J. M.; Dixon, J. A.; deGruyter, J. N.; Baran, P. S. Alkyl Sulfinates: Radical Precursors Enabling Drug Discovery. J. Chem. Med. 2019, 62, 2256-2264.

(16) Moreira, I. de P. R.; Bofill, J. M.; Anglada, J. M.; Solsona, J. G.; Nebot, J.; Romea, P.; Urpí, F. Unconventional Biradical Character of Titanium Enolates. J. Am. Chem. Soc. 2008, 130, 3242-3243.

(17) Heras, C.; Gómez-Palomino, A.; Romea, P.; Urpí, F.; Bofill, J. M.; Moreira, I. de P. R. Experimental and Computational Evidence of the Biradical Structure and Reactivity of Titanium(IV) Enolates. J. Org. Chem. 2017, 82, 8909-8916.

(18) Beaumont, S.; Ilardi, E. A.; Monroe, L. R.; Zakarian, A. Valence Tautomerism in Titanium Enolates: Catalytic Radical Haloalkylation and Application in the Total Synthesis of Neodysidenin. J. Am. Chem. Soc. 2010, 132, 1482-1483.
(19) Gu, Z.; Herrmann, A. T.; Zakarian, A. Dual Ti-Ru Catalysis in the Direct Radical Haloalkylation of $N$-Acyl Oxazolidinones. Angew. Chem. Int. Ed. 2011, 50, 7136-7139.

(20) Li, Y.; Ge, L.; Muhammad, M. T.; Bao, H. Recent Progress on Radical Decarboxylative Alkylation for Csp3-C Bond Formation. Synthesis 2017, 49, 5263-5284.

(21) For recent reports on the use of decarboxylation of diacyl peroxides as a source of radicals, see: (a) Qian, B.; Chen, S.; Wang, T.; Zhang, X.; Bao, H. Iron-Catalyzed Carboamination of Olefins: Synthesis of Amines and Disubstituted B-Amino Acids. J. Am. Chem. Soc. 2017, 139, 13076-13082. (b) Ye, C.; Li, Y.; Zhu, X.; Hu, S.; Yuan, D.; Bao, H. Copper Catalyzed 1,4-Alkylarylation of 1,3-Enynes with Masked Alkyl Electrophiles. Chem. Sci. 2019, 10, 3632-3636.

(22) Davies, S. G.; Sanganee, H. J. 4-Substituted-5,5-dimethyl Oxazolidin-2-ones as Effective Chiral Auxiliaries for Enolate Alkylations and Michael Additions. Tetrahedron: Asymmetry 1995, 6, 671-674.

(23) For the synthesis of non-commercially available diacyl peroxides, see the Supporting Information.

(24) For the X-ray data, see Supporting Information. Crystallographic data for adduct 16c have been also deposited at Cambridge Crystallographic Data Centre as supplementary publication number CCDC 1939369.

(25) For a recent and insightful radical-like approach to the synthesis of $\alpha$-amino acids, see: Ni, S.; Garrido-Castro, A. F.; Merchant, R. R.; de Gruyter, J. N.; Schmitt, D. C.; Mousseau, J. J.; Gallego, G. M.; Yang, S.; Collins, M. R.; Qiao, J. X.; Yeung, K.-S.; Langley, D. R.; Poss, M. A.; Scola, P. M.; Qin, T.; Baran, P. S. A General Amino Acid Synthesis Enabled by Innate Radical Cross-Coupling. Angew. Chem. Int. Ed. 2018, 57, 14560-14565.

(26) Nonhebel, D. C. The Chemistry of Cyclopropylmethyl and Related Radicals. Chem. Soc. Rev. 1993, 22, 347-359.

(27) The calculations were run with the M06 functional, including an implicit solvation model (IEF-PCM, $\mathrm{CH}_{2} \mathrm{Cl}_{2}$ ). See Supporting Information for details.

(28) Tateishi, N.; Mori, T.; Kagamiishi, Y.; Satoh, S.; Katsube, N.; Morikawa, E.; Morimoto, T.; Matsui, T.; Asano, T. Astrocytic Activation and Delayed Infarct Expansion after Permanent Focal Ischemia in Rats. Part II: Suppression of Astrocytic Activation by a Novel Agent $(R)-(-)$-2-Propyloctanoic Acid (ONO2506) Leads to Mitigation of Delayed Infarct Expansion and Early Improvement of Neurologic Deficits. J. Cereb. Blood Flow Metab. 2002, 22, 723-734.

(29) For previous syntheses, see: (a) García, J. M.; Odriozola, J. M.; Lecumberri, A.; Razkin, J.; González, A. Concise and Efficient Route to the Alzheimer's Therapeutic Agent $(R)$-Arundic Acid. Tetrahedron 2008, 64, 10664-10669. (b) Gualandi, A.; Emer, E.; Capdevila, M. G.; Cozzi, P. G. Highly Enantioselective $\alpha$ Alkylation of Aldehydes with 1,3-Benzodithiolylium Tetrafluoroborate: A Formal Organocatalytic $\alpha$ Alkylation of Aldehydes by the Carbenium Ion. Angew. Chem. Int. Ed. 2011, 50, 7842-7846. (c) Pérez, M.; Fañanás-Mastral, M.; Hornillos, V.; Rudolph, A.; Bos, P. H.; Harutyunyan, S. R.; Feringa, B. L. Asymmetric Allylic Alkylation of Acyclic Allylic Ethers with Organolithium Reagents. Chem. Eur. J. 2012, 18, 1188011883.

(30) Beutner, G. L.; Cohen, B. M.; DelMonte, A. J.; Dixon, D. D.; Fraunhoffer, K. J.; Glace, A. W.; Lo, E.; Stevens, J. M.; Vanyo, D.; Wilbert, C. Revisiting the Cleavage of Evans Oxazolidinones with $\mathrm{LiOH} / \mathrm{H}_{2} \mathrm{O}_{2}$. Org. Process Res. Dev. 2019, 23, $1378-1385$. 